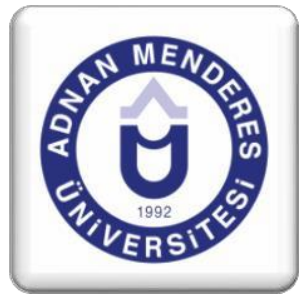

\title{
Proaktif Kişilik Yapısının ve Yenilikçi Davranışın Görev Performansına Etkisi ${ }^{1}$
}

\author{
Sezai TUNCA ${ }^{2}$, Meral ELÇí ${ }^{3}$, Gülay MURAT ${ }^{4}$
}

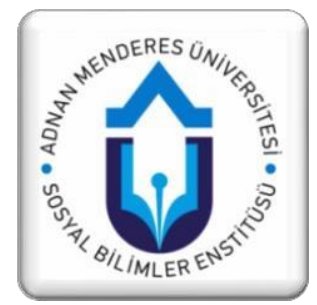

\section{ÖZET}

$\mathrm{Bu}$ araştırma ile proaktif kişilik yapısının ve yenilikçi davranışın, görev performansına anlamlı bir etkisinin olup olmadığını ortaya çıkarma amacı güdülmektedir. Bu amaca yönelik olarak İstanbul, Aydın ve Kocaeli illerinde çeşitli sektörlerde görev yapan 329 çalışana gönüllülük esasına dayalı anket uygulanarak veri toplanmış, toplanan veriler SPSS 17 paket programı ile analiz edilmiştir. Gerçekleştirilen analizler sonucunda hem proaktif kişiliğin hem de yenilikçi davranışların görev performansı üzerinde istatistiki olarak anlamlı ve pozitif yönlü bir etkisinin olduğu tespit edilmiştir.

Anahtar Kelimeler: Proaktif Kişilik, Proaktif Davranış, Yenilikçilik, Yenilikçi Davranış, Görev Performansı.

\section{The Effect of Proactive Personality Structure and Innovative Behaviour on Task Performance}

\begin{abstract}
This research examined the impact of proactive personality structure and innovative behavior on task performance. It is aimed to find out whether the proactive personality structures and innovative behavior of 329 individuals working in different sectors have a meaningful effect on the performance of the task force. For this purpose, data were gathered by the method of survey application to the employees working in various sectors. Hierarchical regression analysis was used to determine the direct and regulatory effects of variables with the generated model. As a result of the analysis, it was determined that the proactive person has a positive effect on task performance and innovative behavior, has a positive effect on task performance.
\end{abstract}

Keywords: Proactive Personality, Proactive Behavior, Innovation, Innovative Behavior, Task Performance

\footnotetext{
${ }^{1}$ Bu çalışmada Sezai Tunca'nın "Proaktif Kişilik Yapısının ve Yenilikçi Davranışın Görev Performansına Etkisi” adlı Yüksek lisans tezinden faydalanılmıștır.

${ }^{2}$ Yüksek Lisans Öğrencisi, Gebze Teknik Üniversitesi, Sosyal Bilimler Enstitüsü, sezaitunca@gmail.com

${ }^{3}$ Doç. Dr., Gebze Teknik Üniversitesi, İşletme Fakültesi, emeral@gtu.edu.tr

${ }^{4}$ Arş. Gör., Gebze Teknik Üniversitesi, İşletme Fakültesi, gulaymurat@gtu.edu.tr
} 


\section{Giriş}

Çağımızın rekabetçi ve zorlu iş ortamı, çalışanlara sorumluluklarını yerine getirmekten daha fazlasını yapmayı gerektirmektedir. İş tanımının ötesinde yapılması gereken işler hakkında sahip olunan yüksek çalışma performansı -öngörülen sorunları ve firsatları kullanmak da dâhil olmak üzere- "proaktif olmak" anlamına gelmektedir. Bu sebeple, çalışanların bireysel inisiyatif alması ve proaktif davranış sergilemesi organizasyonlar için gerekli hale gelmiştir. Böylece; sürekli yenilenerek değişen ve ağır rekabetin yaşandığı koşullarda; işletmeler faaliyetlerini sürdürmek ve uzun süreli ayakta kalabilmek için sorumluluktan kaçmayan, fırsat ve tehditleri görebilen, örgüt için faydalı katkıları olan, verilen görevlerin dışında sorumluluk ve inisiyatif alabilen çalışanlara ihtiyaç duymaktadır (Yolcu ve Çakmak, 2017: 426).

Çalışanların yenilikçi davranışı; rekabet avantajı yaratma (Pieterse et al., 2009) ve önemli performans sonuçlarına ulaşmada yardımcı olduğu için hem işletmeler hem de toplumlar için çok önemli bir hale gelmiştir (Yuan ve Woodman, 2010). İş dünyasında var olan şirketler, genel organizasyonel yeniliğin, bireysel çalışanların yenilikçi davranışlarının güçlendirilmesine büyük ölçüde bağlı olduğu gerçeğini kabul etmektedirler. Bu nedenle, bu tür davranışların işletmelerde geliştirilmesinin yolları ve imkânlarını belirlemek hem uygulayıcılar hem de bilim adamları arasında önemli bir konu haline gelmiştir (De Jong ve Den Hartog, 2010; Demeško, 2017).

Günümüze kadar birçok örgüt, sadece çalışanların iş tanımlarında yazılmış olan gereklilikleri ne kadar iyi gerçekleştirdiği hususunu değerlendirmiştir. Ancak, çağımızda daha az hiyerarşik yapıya ve daha fazla hizmet odaklı örgütlere ihtiyaç duyulmaktadır. Araştırmacılara göre çalışma ortamında performansı oluşturan önemli davranışlardan biri de görev performansıdır (Robbins ve Judge; Akt: Erdem, 2013: 565). Bu kavramlar üzerinde görece daha az araştırma yapılmış olması motivasyonumuzu oluşturduğundan, bu çalışma ile proaktif kişiliğin ve yenilikçi davranışın görev performansı üzerindeki etkilerinin incelenmesi hedeflenmiştir.

\section{Kavramsal Çerçeve ve Hipotezlerin Oluşturulması}

\subsection{Proaktif Kişilik ve Proaktif Davranış}

Proaktif terimi, "pro (önce, ileriye yönelik)" ve "activus (etkin, aktif)" sözcüklerinin birleşiminden oluşmaktadır. Cambridge (2017) sözlügündeki tanıma göre; "proactive" kelimesi sıfat olarak "zamanından önce değişiklik yapllarak önlem alınan; önceden davranılan" anlamina gelmektedir.

Proaktif kişilik için literatürde birçok tanımlama bulunmaktadır. Bateman ve Crant'a (1993: 103) göre proaktif kişiler; çevresel değişimleri gerçekleştirene kadar sabır gösteren kişilerdir. Proaktif kişilik özelliğine sahip bireyler, çevresel değişimi etkileyen, firsatları kollayan, inisiyatif alan, harekete geçebilen, bununla birlikte değişimin öncüleri olarak, diğer çalışanlardan farklı olan kişilerdir (Bateman ve Crant, 1993: 105). Bu yapıya sahip olan kişilerde, mevcut koşulları iyileştirmede veya yenilerini yaratmada inisiyatif kullanma; koşullara pasif olarak adapte olmak yerine statükoya meydan okuma şeklinde davranışlar sergilenir. Proaktif bireyler, davranışa yön veren, geleceğe odaklanan, gerektiğinde eylemlere değişiklik getiren veya kendisini değiştiren kimselerdir (Bindl ve Parker, 2010). Böylece bu kişiler sınırlamaları ve zorlukları önemsemeden, bulundukları çevrede değişim 
yaratırlar (Seibert, Kraimer ve Crant, 1999: 850). Fakat değişimin de sınırları vardır ve bu sebeple, çalışma düzenini ve işleyişi engellemeden olumlu katkılar sağlanmalıdır. Bununla birlikte, proaktif kişilerin diğer çalışanlara nazaran mevcut olan işleyişi değiştirmek istemeleri veya ortamın uygunsuzluğundan memnuniyetsizliklerini seslendirmeleri de olasidir (Crant, 2000: 436).

Proaktif kişilik özelliğine sahip bireyler işin kilit noktalarını iyi öğrenirler, firsatları sezerler, sorgulayarak sorumluluk alırlar, çıkış noktası ararlar ve harekete geçerler, bunun yanı sıra öğrenmeye daha fazla açıktırlar ve geri bildirimleri takip ettikleri için daha fazla bilgi sahibi olurlar. Aynı zamanda örgüt kültürleri ile sosyal ilişkiler ağı oluşturmada, etrafındaki insanlar ile etkileşimde bulunmada ve örgüte uyum konusunda da diğer bireylere göre daha başarılıdırlar. Böylece kendi "sosyal sermayelerini" oluştururlar. Çalışma gruplarındaki etkili sosyal ilişkiler sonucunda işlerini daha çok severler ve en iyi şekilde yaparlar, bunların sonucunda da kalitede artış sağlanır (Lambert, Eby ve Reeves, 2006: 351-365). Ayrıca, kendi iş ortamlarını etkileyerek kendi lehlerine çevirirler. Yatay ve dikey konumlardaki bireylerle bağlantı kurarlar, kariyerleriyle yakından ilgilenirler ve engeller karşında azim gösterirler (Seibert, Kraimer ve Crant, 1999: 416-427). İşletmeler yenilenmeye ve girişimci çalışanlara ihtiyaç duyarlarsa proaktif çalışanları tercih etmelidirler. Fakat bu tip çalışanların işten ayrılıp kendi işyerlerini kurma ihtimallerinin yüksek olduğu da unutulmamalıdır (Becherer ve Maurer,1999: 26-28).

Proaktif davranış ise proaktif kişilikten kaynaklanır ve mevcut durumu kendiliğinden değiştirecek ya da değiştirme niyetiyle başlatılmış eylemlerdir (Bindl ve Parker, 2010). Diğer bir ifadeyle çalışanların kendilerini ve çevrelerini etkilemek için yaptıkları davranışlardır (Grant ve Ashford, 2008: 8). Proaktif davranışa sahip çalışanlar; geribildirim alma, iş tanımının ötesine geçme, kendisini geliştirme, inisiyatif kullanma ve müşterilerle yakından ilgilenme gibi proaktif davranışlarla meşgul olma eğilimindedirler (Yolcu ve Çakmak, 2017).

\subsection{Yenilik, Yenilikçilik ve Yenilikçi Davranış}

West ve Farr (1990) yeniliği; bireye, gruplara veya kuruluşlara önemli derecede fayda sağlayacak şekilde tasarlanan fikirler, süreçler, ürünler ya da prosedürler olarak açıklamıştır. Jain'e (2010) göre yenilik; yenilik yapan kişiler ile yenilikten etkilenenler arasında bir toplumsal etkileşim sürecidir ve birinin eyleminin diğerlerini etkileyeceğini kabul eder. Kisacası yenilik yapmak "yenilik getirmek, değişiklik yapmak" demektir.

Yenilikçilik ise, yeni bir ürün yapmak veya servis geliştirmek anlamına gelen Latince "innovare" sözcüğünden türetilmiştir. Süreç olarak "yenilemeyi", sonuç olarak da "yeniliği" belirten yenilikçilik (inovasyon), OECD literatürüne göre "pazarlanabilir bir düşünce, ürün ya da hizmeti, yeni ya da geliştirilmiş bir imalat ya da dağıtım yöntemine, bir toplumsal hizmet yönetimine dönüştürmek”tir.

İşletmelerin yenilikçi politikalar oluşturup bunu hayata geçirmeleri, rekabet üstünlügünü elde etmede önemli hale gelmiştir. Bu şekilde işletmeler çalışanları ile birlikte yeni yöntem, yeni hizmet ya da yeni ürünler sunarak rakipleri karşısında avantaj sağlayacaktır (Çalışkan, 2013).

Yenilikçi davranış ise; bir çalışanın, yeni fikirleri, ürünleri, süreçleri ve yöntemleri oluşturmasına ve uygulamasına yönelik eylemidir (Kheng, June ve Mahmood, 2013). Diğer bir tanımlamaya göre, grupta veya organizasyonda, rol performansına, gruba veya organizasyona fayda sağlamak için yeni fikirlerin bilinçli oluşturulması, tanıtılması ve uygulanmasıdır (Jannsen, 2000). Scott ve Bruce (1994), bireysel yenilikçi davranış1; dört 
etkileşim sisteminin "birey, lider, çalışma grubu ve yenilik için iklimin" bir sonucu olarak görmüştür. Oukes (2010) ise yenilikçi davranış1; "rol performansl, grup ya da organizasyondan fayda sağlamak için bir iş rolü, grup ya da organizasyonda yeni fikirlerin kasitl yaratılması, tanitılması ve uygulanması" olarak tanımlanmaktadır.

\subsection{Görev Performansı}

Görev performansı, görevsel iş tanımında yer alan temel dönüşümlerin sağlanmasına ve eylemlerin gerçekleştirilmesine ait performanstır (Befort ve Hattrup, 2003: 18). Bir mal ya da hizmetin üretimine ya da yönetim görevlerine katkıda bulunmaya dönük sorumlulukları içerir. $\mathrm{Bu}$ eylem, geleneksel iş tanımındaki görevlerin birçoğunu içermektedir (Robbins ve Judge: Akt: Erdem, 2013: 565). Diğer bir ifadeyle, bir faaliyet esnasında yapılması gereken temel sorumlulukları ifade eder ve faaliyetler bir işten diğerine göre değişmektedir (Jawahar ve Carr, 2007: 332). Bireylerin mesleki anlamda yeterlilikleri, iş ortamının elverişliliği, tam olarak tanımlanmış görevler ve etik özellikler görev performansının tam anlamıyla yerine getirilmesinde etkili olan unsurlardır (Özdevecioğlu ve Kanıür, 2009: 59). Örgütsel yaklaşım olarak performans, çalışanın katkı düzeyine göre ölçülebilen, örgüt hedef ve amaçlarına uygun olan eylem ya da davranışlardır (Suliman, 2001: 1050). Görev performansı, şekilsel iş tanımları kapsamında ana dönüşümlerin gerçekleştirilmesi ve eylemlerin yerine getirilmesine yönelik performans türüdür. $\mathrm{Bu}$ kapsamda, görev performansının işin ustalık ve mesleki yönüyle alakalı olduğu söylenebilir. Başka bir söylemle, görev performansı faaliyetler arasında görülen farklılıkları ortaya çıkaran işe ait değişmeyen görev ve sorumlulukları ifade etmektedir (Jawahar ve Carr, 2007: 330).

\subsection{Proaktif Kişilik ve Yenilikçi Davranış ile Görev Performansı Arasındaki İlişkilerin Araştırılması}

\subsubsection{Proaktif Kişilik ve Görev Performansı}

Borman ve Brush, (1993: 1-21) görev performansını, iş performansının alt bileşeni şeklinde tanımlamış ve a) işe özgü görev yeterliliği, b) işe özgü olmayan görev yeterliliği, c) yazılı ve sözlü iletişim yetkinliği, d) liderlik pozisyonunda denetim ve e) kısmen yönetim / idare şeklinde ifade etmiştir. Bu tanıma uygun yapılan araştırmalar ile proaktif kişilik ile iş performansı arasındaki ilişki incelenirken görev performansı bileşeni de incelenmiştir.

Thomas, Whitman ve Viswesvaran (2010: 276) tarafından proaktiflik ve iş performans1 arasındaki ilişki incelenmiş, araştırmaya katılan 5045 katılımcı verileri ile birbirinden bağımsız 25 çıktı birleştirilerek, elde edilen araştırma bulgularının istatistiksel analizi yapılmıştır. İki değişken arasındaki ilişki güçlü olmasa da, istatistiksel olarak anlamlı olduğu tespit edilmiştir Chan, (2006: 475-481) proaktif kişilik ve görev performansı arasındaki ilişkiyi "Proaktif Kişilik Ölçeği”ni kullanarak; 139 çalışandan oluşan bir örneklem üzerinde incelemiştir. Araştırma sonucunda; proaktif kişiliği yüksek olan çalışanların durumu düzeltmek için iyi kararlar aldıkları gözlenmiş ve proaktif kişiliğin görev performansını pozitif yönde etkilediği sonucuna varılmıştır. Yukarıda bahsedilen bu çalışmalar doğrultusunda; aşağıdaki hipotez önerilmektedir:

\section{$H_{1}$ : Proaktif kişilik yapısı görev performansını pozitif yönde etkilemektedir.}

\subsubsection{Yenilikçi Davranış ve Görev Performansı}

Yenilikçi davranışın yaratıcılık bileşeni, "verilen görevi yaparken yararlı olan yenilikleri üretmektir" (Amabile, 1996). Deneysel kanıtlar; yaratıcılığın bireysel görev performansı ile pozitif yönde ilişkili olduğunu göstermektedir (Gilson, 2008; Gong, Huang ve Farh, 2009; Dörner, 2012). 
Yenilikçi davranış, yenilik yoluyla kendini veya çalışma ortamını değiştirmeyi gerektirir (Janssen, van de Vliert ve West, 2004). Bu doğrultuda; yenilikçi davranış, çalışanların işe etkili bir şekilde uyum sağlaması ve böylece beklenen görev performansının iyileştirilmesine yardımcı olması anlamına gelmektedir (Dörner, 2012).

Aryee, Walumbwa, Zhou ve Hartnell (2012: 1-25) yenilikçi davranış ile görev performans1 arasındaki ilişkiyi Çin'deki 30 çalışan üzerinde test etmişlerdir. Gerçekleştirilen araştırmaya göre; yenilikçi davranış ve görev performansı arasında pozitif yönlü bir ilişki olduğu tespit edilmiştir. Bu çalışmalardan yola çıkılarak; aşağıdaki hipotezi önermek mümkündür:

$\mathrm{H}_{2}$ : Yenilikçi davranış görev performansını pozitif yönde etkilemektedir.

\section{Araştırmanın Metodolojisi}

\subsection{Araştırmanın Amacı, Örneklem ve Araştırma Modeli}

$\mathrm{Bu}$ araştırmanın amacı, işgörenlerin proaktif kişiliğe veya yenilikçi davranışa sahip olmalarının, görev performansına etkisini incelemektir. Bu etkiyi incelemek üzere hazırlanan anket formu, gönüllü katılım esasına dayalı olarak 329 kişiye uygulanmıştır. Araştırmanın örneklemini, özel ve kamu sektörlerinde çalışan yönetici, öğretim elemanı, öğretmen ve idari personel kadrosunda görev yapmakta olan işgörenler oluşturmaktadır. Katılımcıların çoğunluğu İstanbul, Aydın ve Kocaeli'de çalışan bireylerdir.

Proaktif kişiliğin ve yenilikçi davranışın görev performansına olan etkisinin incelendiği bu araştırmaya ait araştırma modeli Şekil 3.1'de gösterilmektedir:

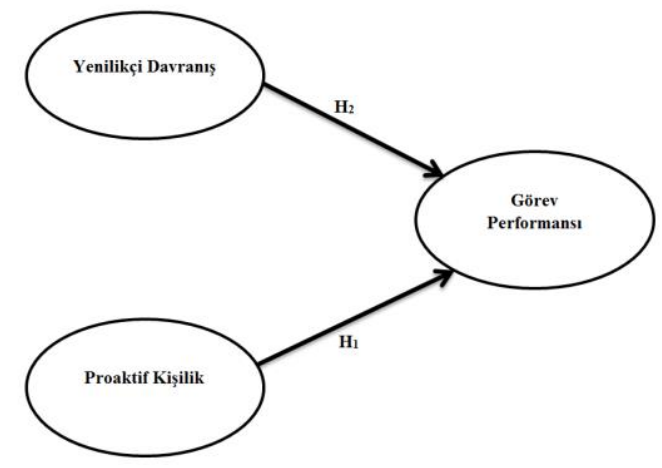

Şekil 3.1. Araştırma Modeli

\subsection{Veri Toplama Araçları}

Araştırmada uygulanan anketler için 5'li Likert ölçeği kullanılmıştır. Proaktif kişilik yapısı, yenilikçi davranış ve görev performansına ilişkin değerlendirme seçenekleri şu şekilde belirlenmiştir; "1- Kesinlikle Katılmıyorum, 2- Katılmıyorum, 3- Kararsızım, 4-Katılıyorum ve 5- Kesinlikle Katılıyorum". Anket formunun ilk bölümüne anketin amacı, içeriği ve bilimsel yararına ilişkin bir ifade belirtilerek, anketi dolduran katılımcılardan isim bilgisi alınmamıştır. Böylece ankete olan güvenin artması, anket geçerliliğinin kuvvetlendirilmesi ve geri dönüş oranının artırılması hedeflenmiştir. 
Araştırma için öngörülen hipotezlerin test edilmesi maksadıyla literatür detaylıca incelenmiş ve daha önce akademik çalışmalarda kullanılan geçerliliği ve güvenirliği test edilerek onaylanmış ölçekler çalışma kapsamına alınmıştır. Proaktif kişilik özelliklerinin birey tarafindan taşınıp taşınmadığını ölçmek amacıyla Bateman ve Crant (1993) tarafından oluşturulan Proaktif Kişilik Ölçeği (17 ifade) kullanılmıştır. Yenilikçi davranışların ölçülmesi için Scott ve Bruce (1994) tarafindan uyarlanan ölçekten (6 ifade); Görev performansının ölçülmesi için de Williams ve Anderson (1991) tarafından geliştirilen 7 ifadeden oluşmuş bir ölçekten faydalanılmıştır.

\subsection{Analiz ve Bulgular}

Gerçekleştirilen araştırmada, 329 çalışandan elde edilen veriler, SPSS 17 istatistik programı ile analiz edilmiştir. Bu bölümde, çalışmaya ait demografik veriler, faktör analizi, geçerlilik analizi, güvenilirlik analizi, korelasyon ve regresyon analizleri ve bu analizlere ait bulgu ve yorumlar sunulmaktadır.

\subsection{1. Örnekleme Ait Demografik Veriler}

Ankete cevap veren kişilerin yaş dağılımları; $18-25$ yaş \%35,88; $25-29$ yaş $\% 19,47 ; 30-34$ yaş $\% 14,12 ; 35-39$ yaş $\% 11,83 ; 40$ yaş ve üzeri $\% 18,70$ 'tir. Katılımcıların çalışma süresi dağılımları; 5 yıldan az $\% 54,67 ; 5-9$ y11 \%23,11; $10-14$ y11 \%9,33; $15-19$ y1 $\% 4.89$ ve 20 y1 ya da üzeri \%8,00'dir. Katılımcıların \%44,98'i kadın, \%51,06's1 erkektir. Özel şirkette çalışanlar \%25,00; kamu şirketinde çalışanlar \%72,43; yabancı ya da karma sektörlerde çalışanlar ise \%2,57'dir. Katılımcıların çalıştıkları pozisyona göre dağılımları; personel $\% 79,23$; alt düzey yönetici $\% 7,39$; orta düzey yönetici $\% 8,45$; üst düzey yönetici $\% 3,87$; iş ortağ 1 ya da patron $\% 1,06$ şeklindedir.

\subsubsection{Geçerlilik Analizi}

Verilere faktör analizi uygulanmadan önce, elde edilen verilerin faktör analizine uygun olup olmadığını saptamak amacıyla Kaiser-Meyer-Olkin (KMO) ve ve Barlett testleri uygulanmıştır (Bkz. Tablo 3.1).

Tablo 3.1. KMO and Bartlett's Testleri Tablosu

\begin{tabular}{|ll|c|}
\hline Kaiser-Meyer-Olkin (KMO) & &, 895 \\
Bartlett's Testi & Approx. Chi-Square & 4513,743 \\
& df & 435 \\
& Sig. &, 000 \\
\hline
\end{tabular}

KMO değeri 0,895 > 0,50 olduğundan veriler faktör analizi yapmaya uygundur. Bunun yanı sıra Barlett's Testindeki sigma değeri 0.05 değerinden küçük olduğu için de verilerin faktör analizine uygun olduğunu ifade edebiliriz.

\subsubsection{Faktör Analizi}

Veri setine uygulanan faktör analizinde veriler istenilen boyutlarda olmadığından 4 soru değerlendirme dışı bırakılarak faktör analizi tekrar gerçekleştirilmiştir. Gerçekleştirilen faktör analizinde faktör dağılımları ve faktör yükleri uygun olan, 3 boyut saptanmıştır (Bkz. Tablo 3.2). 
Tablo 3.2. Faktör Analizi Tablosu

\begin{tabular}{|c|c|c|c|}
\hline & & Bileşenler & \\
\hline & $\begin{array}{l}\text { Proaktif } \\
\text { Kişilik }\end{array}$ & $\begin{array}{c}\text { Görev } \\
\text { Performans1 }\end{array}$ & $\begin{array}{l}\text { Yenilikçi } \\
\text { Davranı̧̧ }\end{array}$ \\
\hline p16- İyi bir firsatı diğerleri görmeden çok önce yakalayabilirim. & ,666 & & \\
\hline p15- Problemleri firsatlara çevirmekte mükemmelimdir. & ,643 & & \\
\hline $\begin{array}{l}\text { p2- Kendimi bulunduğum toplumda ya da dünyada değişiklik yapacak } \\
\text { düzeyde hırslı hissediyorum. }\end{array}$ & ,625 & & \\
\hline p10- Fırsatları görmekte başarılıyımdır. & ,618 & & \\
\hline p12- Eğer bir fikre inanırsam hiçbir engel bunu yapmamı engelleyemez. & ,616 & & \\
\hline p13- Statükoya meydan okumayı severim. & ,613 & & \\
\hline $\begin{array}{l}\text { p4- Nerede olursam olayım her zaman yapıcı değişiklikler yapma gücünü } \\
\text { kendimde bulmuşumdur. }\end{array}$ &, 547 & & \\
\hline p8- Eğer bir şeye inanıyorsam sıradışılığına bakmaksızın onu yaparım. & ,526 & & \\
\hline $\begin{array}{l}\text { p9- Diğerlerine muhalefet olacağımı bilsem de fikirlerimi savunmaktan } \\
\text { keyif duyarım. }\end{array}$ & ,486 & & \\
\hline p5- Fikirlerime olan direnç ve engeller ile karşılaşmaktan keyif duyarım. & 466 & & \\
\hline $\begin{array}{l}\text { p6- Başka hiçbir şey fikirlerimin gerçeğe dönüşmesinden daha heyecan } \\
\text { verici olamaz. }\end{array}$ & ,454 & & \\
\hline p1- Hayatımı iyileştirmek (geliştirmek) için sürekli yeni yollar ararım. & 453 & & \\
\hline p11- Yapılacak şeyler için her zaman daha iyi yollar ararım. & 450 & & \\
\hline ta3- Benden beklenen görevleri yerine getiririm. & & ,850 & \\
\hline ta2- İş tanımımda belirtilen sorumlulukları yerine getiririm. & & 829 & \\
\hline $\begin{array}{l}\text { ta4- Benden beklenen asgari (temel) performans beklentilerini yerine } \\
\text { getiririm. }\end{array}$ & & ,784 & \\
\hline ta7- Bana verilen temel görevleri başarılı bir şekilde yerine getiririm. & & ,716 & \\
\hline ta1- Bana verilen görevleri yeterli düzeyde yerine getiririm. & & ,715 & \\
\hline ta6- İşimin yapmak zorunda olduğum kısımlarını ihmal etmem. & & ,702 & \\
\hline $\begin{array}{l}\text { ta5- Performans değerlendirmemi direkt etkileyecek faaliyetlerde } \\
\text { bulunurum. }\end{array}$ & & ,452 & \\
\hline ye2- İşimle ilgili yaratıcı fikirler üretirim. & & & ,801 \\
\hline $\begin{array}{l}\text { ye5- İşimde yeni teknolojileri, süreçleri, teknikleri ve ürün fikirlerini } \\
\text { araştırırım. }\end{array}$ & & & ,766 \\
\hline ye1- İşimle ilgili yenilikçiyimdir. & & & ,763 \\
\hline ye4- Yeni fikirlerin uygulanmasına yönelik kaynakları araştırır ve korurum. & & & ,738 \\
\hline $\begin{array}{l}\text { ye6- Yeni fikirlerin uygulanmasına yönelik yeterli düzeyde plan ve } \\
\text { programları geliştiririm. }\end{array}$ & & & 625 \\
\hline ye3- Başkalarının fikirlerini destekler ve savunurum. & & & ,593 \\
\hline
\end{tabular}




\subsubsection{Güvenilirlik Analizi, Korelasyon Analizi ve Tanımlayıcı İstatistikler}

Araştırmadaki 329 katılımcının değişkenlere verdiği puanların ortalamaları ve standart sapmaları Tablo 3.3'de gösterilmiştir. Faktörlerin güvenilirliklerini ölçmek amacıyla, güvenilirlik analizi gerçekleştirilmiştir. Tüm faktörler için hesaplanan Cronbach's Alpha değerleri 0,70 'den büyük olduğundan faktörlerin güvenilir olduğu ifade edilebilir. Değişkenler arasındaki ilişkiyi anlamaya yönelik gerçekleştirilen korelasyon analizi tabloda verilmiştir (Tablo 3.3).

Tablo 3.3. Değişkenlere ait Tanımlayıcı İstatistikler, Güvenilirlik Analizi ve Korelasyon Analizi

\begin{tabular}{|l|l|l|l|c|c|}
\hline Değişken & Ortalama & Std. Sapma & $\begin{array}{l}\text { Cronbach's } \\
\text { Alpha Değerleri }\end{array}$ & Proaktif Kişilik & $\begin{array}{c}\text { Görev } \\
\text { Performans1 }\end{array}$ \\
\hline Proaktif Kişilik & 3,6248 &, 58985 &, 845 & 1 & \\
\hline Görev Performans1 & 4,2366 &, 61375 &, 887 & $\mathbf{, 4 3 3}^{* *}$ & 1 \\
\hline Yenilikçi Davranış & 3,9422 &, 72756 &, 876 & $\mathbf{5 7 1}^{* *}$ & $\mathbf{, 6 2}^{* *}$ \\
\hline
\end{tabular}

Elde edilen korelasyon bulgularına göre; gerek görev performansı ile proaktif kişilik arasında, gerek yenilikçi davranış ve proaktif kişilik arasında ve gerekse proaktif kişilik ile yenilikçi davranış arasında 0.01 anlamlılık düzeyinde pozitif yönlü ve istatistiki olarak anlamlı bir ilişki bulunmaktadır.

\subsubsection{Regresyon Analizi}

Bağımsız değişkenin bağımlı değişken üzerinde istatistiki olarak anlamlı bir etkisinin olup olmadığını anlamaya yönelik gerçekleştirilen regresyon analizi sonuçları Tablo 3.4'da sunulmuştur.

Tablo 3.4. Regresyon analizi

\begin{tabular}{|c|c|c|c|c|c|}
\hline \multirow[t]{2}{*}{ Model } & \multicolumn{2}{|c|}{ Standardize Edilmemiş Katsayılar } & \multirow{2}{*}{\begin{tabular}{|c|} 
Standardize Katsayılar \\
Beta
\end{tabular}} & \multirow[b]{2}{*}{$\mathrm{t}$} & \multirow[b]{2}{*}{ Sig. } \\
\hline & $\mathrm{B}$ & Std. Hata & & & \\
\hline (Sabit) & 2,056 & 184 & & 11,158 & 000 \\
\hline Proaktif Kişilik & ,172 & ,057 &, $166^{* *}$ & 3,011 & ,003 \\
\hline Yenilikçi Davranış & ,395 & ,046 & $468 * *$ & 8,505 & ,000 \\
\hline
\end{tabular}

Bağımlı Değişken: Görev Performansı

Regresyon analizi neticesinde Model $\left(\mathrm{R}^{2}=0,331, \mathrm{~F}=82,049\right.$, Sig. 0,000) anlaml bulunmuştur. Elde edilen bulgulara göre; proaktif kişiliğin, görev performansı üzerinde pozitif yönlü ve istatistiki olarak anlamlı bir etkisi olduğu saptanmıştır $(\operatorname{sig}<0.05)$. Aynı 
şekilde; yenilikçi davranışın da görev performansı üzerinde pozitif yönlü ve istatistiki olarak anlamlı bir etkisi olduğu bulgulanmıştır.

Gerçekleştirilen regresyon analizinden elde edilen bu bulgulardan hareketle;

- $\mathrm{H}_{1}$ : Proaktif kişilik yapısı görev performansını pozitif yönde etkilemektedir;

- $\mathrm{H}_{2}$ : Yenilikçi davranış görev performansını pozitif yönde etkilemektedir;

Şeklinde oluşturulan her 2 hipotez de kabul edilmiştir.

\section{Sonuç ve Öneriler}

Rekabetin hızla artarak küresel boyuta ulaştı̆̆ı günümüz koşullarında organizasyonlar, varlıklarını sürdürebilmek, değişen koşullara uyum sağlayabilmek, hatta değişimlerin öncüsü olabilmek için; sorumluluk bilinci yüksek, inisiyatif alabilen, kendilerine verilen görevleri maksimum çaba ile gerçekleştirebilen ve hatta tanımlı görevlerinin dışında dahi aktif roller üstlenen çalı̧̧anlara ihtiyaç duymaktadırlar. İfade edilen özelliklere sahip işgörenler, örgütün amaç ve hedefleri doğrultusunda çalışarak, bağlı oldukları organizasyonlara önemli katkılar sunmaktadırlar. Bu bireyler, sahip oldukları iş ve sorumluluk bilinciyle yüksek görev performans1 elde ederek hem kendilerinin hem de örgütlerinin gelişmesi konusunda belirleyici rol oynar. İşgörenlerin yüksek görev performansı elde etmeleri için sahip olması gereken iki önemli özelliğin yenilikçi davranış ve proaktif kişilik olduğu düşünülmektedir. $\mathrm{Bu}$ bağlamda araştırmamızın amac1; proaktif kişiliğin ve yenilikçi davranışın görev performans1 üzerindeki etkilerini ampirik olarak incelemektir. Gerçekleştirilen analizler neticesinde, hem proaktif kişiliğin hem de yenilikçi davranışın görev performansı üzerinde istatistiki olarak anlamlı ve pozitif bir etkisinin olduğu saptanmıştır. Dolayısıyla görev performansını arttırmada proaktif kişiliğin ve yenilikçiliğin önemli unsurlar olduğunu ifade edebiliriz.

Araştırmamızın bazı kısıtları bulunmaktadır. Çalışma, Marmara Bölgesinde farklı sektörlerde çalışan bireylerle gerçekleştirilmiştir. Spesifik bir sektörde veya diğer coğrafi bölgelerde gerçekleştirilecek çalışmalarda sonuçlar farklılık gösterebilir. Bunun yanısıra daha geniş bir örneklem grubu ile genelleyici sonuçların elde edilme olasılığı artacaktır.

Gerçekleştirilen araştırmanın hem uygulamalı hem de teorik katkıları vardır. Çalışma bulguları göz önüne alındığında yöneticilere bazı öneriler sunulabilir. Öncelikle; görev performansını arttırmak için yenilikçiliğin ve proaktifliğin desteklenmesi önemlidir. $\mathrm{Bu}$ doğrultuda, yöneticiler işe alım süreçlerinde proaktif çalışanları tercih edebilirler. Bunun yanısıra, yenilikçi davranışları ve yenilikçi örgüt kültürünü destekleyen uygulamalar ve politikalar benimseyebilirler. İşgörenlerin; gereken şartlarda risk alabilmesi, kendini doğru ve açık bir şekilde ifade edebilmesi, değişen iş ve sektör koşullarına hızlı bir şekilde adapte olabilmesi, sorgulayarak sorumluluk alabilmesi ve yetkinliklerini geliştirebilmesi için eğitim firsatları sağlanabilir. Bu konuda çalışma yapmak isteyen araştırmacılara da bazı önerilerde bulunulabilir. İncelenen değişkenler arasındaki ilişkide liderlik, örgüt kültür ve iklimi gibi kavramların etkisi araştırılabilir. Daha büyük bir örneklem ile veya spesifik bir sektör üzerine çalışmalar yapılabilir. Sektörel, bölgesel ve hatta ülkeler arası karşılaştırmalı incelemeler yapılabilir. 


\section{KAYNAKÇA}

AMABİLE, T. M. (1996). Creativity in context: Update to the social psychology of creativity. Hachette UK.

ARYEE, S., WALUMBWA, F. O., ZHOU, Q., \& HARTNELL, C. A. (2012). Transformational leadership, innovative behavior, and task performance: Test of mediation and moderation processes. Human Performance, 25(1), 1-25.

BATEMAN, T. S., \& CRANT, J. M. (1993). The proactive component of organizational behavior: A measure and correlates. Journal of organizational behavior, 14(2), 103118.

BECHERER, R. C., \& MAURER, J. G. (1999). The proactive personality disposition and entrepreneurial behavior among small company presidents. Journal of small business management, 37(1), 28-36.

BEFORT, N., \& HATTRUP, K. (2003). Valuing task and contextual performance: Experience, job roles, and ratings of the importance of job behaviors. Applied HRM Research, 8(1), 17-32.

BİNDL, U. K., \& PARKER, S. K. (2010). Proactive work behavior: Forward-thinking and change-oriented action in organizations. APA handbook of industrial and organizational psychology, 2, 567-598.

CHAN, D. (2006). Interactive effects of situational judgment effectiveness and proactive personality on work perceptions and work outcomes. Journal of Applied Psychology, 91(2), 475.

BORMAN, W. C., \& BRUSH, D. H. (1993). More progress toward a taxonomy of managerial performance requirements. Human performance, 6(1), 1-21.

CRANT, J. M. (2000). Proactive behavior in organizations. Journal of management, 26(3), 436.

ÇALIŞKAN, A. (2013). İç Odaklı Örgüt Kültürünün Yenilikçi Davranışa Etkisinde Personel Güçlendirmenin Aracılık Rolü. Is, Guc: The Journal of Industrial Relations \& Human Resources, 15(1).

DE JONG, J., \& DEN HARTOG, D. (2010). Measuring innovative work behaviour. Creativity and Innovation Management, 19(1), 23-36.

DEMEŠKKO, N. (2017). Effects of transformational and transactional leadership styles on innovative work behavior: the role of employee's locus of control(Doctoral dissertation, ISM University of Management and Economics).

DÖRNER, N. (2012). Innovative work behavior: The roles of employee expectations and effects on job performance. University of St.Gallen, Doctor of Philosophy, Germany.

GILSON, L. L. (2008). Why be creative: A review of the practical outcomes associated with creativity at the individual, group, and organizational levels. Handbook of organizational creativity, 303-322.

GONG, Y., HUANG, J. C., \& FARH, J. L. (2009). Employee learning orientation, transformational leadership, and employee creativity: The mediating role of employee creative self-efficacy. Academy of management Journal, 52(4), 765-778.

GRANT, A. M., \& ASHFORD, S. J. (2008). The dynamics of proactivity at work. Research in organizational behavior, 28, 3-34.

JANSSEN, O. (2000). Job demands, perceptions of effort-reward fairness and innovative work behaviour. Journal of Occupational and organizational psychology, 73(3), 287302.

JANSSEN, O., VAN DE VLIERT, E., \& WEST, M. (2004). The bright and dark sides of individual and group innovation: A special issue introduction. Journal of Organizational Behavior, 25(2), 129-145. 
JAİN, R. (2010). Innovation in organizations: A comprehensive conceptual framework for future research. South Asian Journal of Management, 17(2), 81-111.

JAWAHAR, I. M., \& CARR, D. (2007). Conscientiousness and contextual performance: The compensatory effects of perceived organizational support and leader-member exchange. Journal of Managerial Psychology, 22(4), 330-349.

LAMBERT, T. A., EBY, L. T., \& REEVES, M. P. (2006). Predictors of networking intensity and network quality among white-collar job seekers. Journal of career development, 32(4), 351-365.

KHENG, Y. K., JUNE, S., \& MAHMOOD, R. (2013). The determinants of innovative work behavior in the knowledge intensive business services sector in Malaysia. Asian Social Science, 9(15), 47-59.

OUKES, T. (2010). "Innovative work behavior", University of Twente, Bachelor thesis, Holland.

PİETERSE, A. N., VAN KNIPPENBERG, D., SCHIPPERS, M., \& STAM, D. (2010). Transformational and transactional leadership and innovative behavior: The moderating role of psychological empowerment. Journal of organizational behavior, 31(4), 609-623.

ROBBİNS, S. P., \& JUDGE, T. A. (2013). "Örgütsel davranış.” (İ. Erdem, Çev.) Ankara: Nobel Akademik Yayıncılık.

SEIBERT, S. E., CRANT, J. M., \& KRAİMER, M. L. (1999). Proactive personality and career success. Journal of applied psychology, 84(3), 416-427.

SCOTT, S. G., \& BRUCE, R. A. (1994). Determinants of innovative behavior: A path model of individual innovation in the workplace. Academy of management journal, 37(3), 580-607.

SULIMAN, A. M. (2001). Work performance: is it one thing or many things? The multidimensionality of performance in a Middle Eastern context. International Journal of Human Resource Management, 12(6), 1049-1061.

ÖZDEVECIOGGLU, M., \& KANIGÜR, S. (2009). Çalışanların ilişki ve görev yönelimli liderlik algılamalarının performansları üzerindeki etkileri. Karamanoğlu Mehmetbey Üniversitesi Sosyal Ve Ekonomik Araştırmalar Dergisi, 2009(1), 53-82.

THOMAS, J. P., WHITTMAN, D. S., \& VISWESVARAN, C. (2010). Employee proactivity in organizations: A comparative meta-analysis of emergent proactive constructs. Journal of Occupational and Organizational Psychology, 83(2), 275-300.

UNCUOĞLU YOLCU, İ., \& ÇAKMAK, A. F. (2017). PROAKTIF KISŞILIK İLE PROAKTIF ÇALIȘMA DAVRANIȘI İLISSKİSI ÜZERİNDE PŞIKOLOJIKK GÜÇLENDIRMENIN ETKİII. Uluslararası Yönetim iktisat ve İşletme Dergisi, 13(2), 425-438.

WEST, M.A., AND FARR, J.L. (1990) Innovation at work. In M.A. West and J.L. Farr (Eds), Innovation and creativity at work: Psychological and organizational strategies (pp. 3-13). Chichester, England: Wiley.

WILLIAMS, L. J., \& ANDERSON, S. E. (1991). Job satisfaction and organizational commitment as predictors of organizational citizenship and in-role behaviors. Journal of management, 17(3), 601-617.

YUAN, F., \& WOODMAN, R. W. (2010). Innovative behavior in the workplace: The role of performance and image outcome expectations. Academy of Management Journal, 53(2), 323-342. 